\title{
Measurement of Moisture Content and Volume Change Distribution Inside Cement Paste Specimens Using X-Ray CT Imaging
}

\author{
Takayuki Fumoto ${ }^{1}$, Masaru Abuku ${ }^{2}$ and Stephen A. Hall ${ }^{3}$ \\ ${ }^{1}$ Department of Civil and Environmental Engineering, Faculty of Science and Engineering, Kindai \\ University, 3-4-1, Kowakae, Higashi-osaka, 577-8502, Osaka, Japan, fumoto@civileng.kindai.ac.jp \\ ${ }^{2}$ Department of Architecture Faculty of Architecture, Kindai University, 3-4-1, Kowakae, Higashi- \\ osaka, 577-8502, Higashi-osaka, Osaka, Japan, abuku@arch.kindai.ac.jp \\ ${ }^{3}$ Department of Solid mechanics, Faculty of Engineering, Lund University, P.O. Box 118 \\ SE-221 00, Lund, Sweden, Stephen.Hall@solid.lth.se
}

\begin{abstract}
The purpose of this study was to clarify the internal change of concrete structures during drying. Therefore, we used X-ray CT to investigate water content and volume changes inside cement paste specimens during drying. Changes in the CT image intensities and measurements on the images indicated water content and volume changes, including local changes detected with digital volume correlation. Next steps will be to understand the link between volume changes and the local water content.
\end{abstract}

Keywords: Cement Past, Drying Shrinkage, Moisture Content, X-Ray CT, Digital Volume Correlation.

\section{Introduction}

Concrete contains a lot of free water. When free water evaporates by drying, volume changes can occur. Such volume changes due to drying can cause cracks on the surface of concrete structures, resulting in a decreased durability of the structure.

The estimation of volume changes in concrete have usually been calculated based on the length change of a specimen (JIS A 1129-3). However, it is not only the shrinkage of cement paste that should be considered, but also shrinkage and distribution of aggregates also influence volume changes in concrete, for example Zhanga, W. et al (2013) and Alexander, MG. (1996). Furthermore, as moisture is transferred from the surface, the moisture content is different between the surface and the interior. For these reasons, it is difficult to estimate the complicated volume change only by the apparent externally measured size change of a specimen.

For the above reasons, we considered that a method that can measure the moisture content and volume change inside concrete in three dimensions (3D) is necessary. Previously, Sant, G. and Weiss, J. (2009). and Hong, S., et al (2019) used an X-ray CT apparatus to mesurement changing of water content and cracking inside the specimen. T. Fumoto also developed an Xray $\mathrm{CT}$ system to estimate moisture content and composition of concrete after high temperature heating and to measure $3 \mathrm{D}$ volumetric strain fields in concrete under loading stress, for example Fumoto, T. and Hall, S (2019) and Fumoto, T., Mizuno, S. and Ozawa, M. (2016). Here we extend this previous work to examine the moisture content and volume change inside specimens during drying.

In this study we performed a length-change test on a cylindrical specimen of cement paste, which is a basic approach for measuring drying shrinkage, but we study the distribution of volume changes inside the sample using $\mathrm{X}$ ray $\mathrm{CT}$ and make image measurements at different 
stages of the drying.

\section{Experiment Methods}

\subsection{Specimen}

To maximise the possibility of being able to make 3D measurements of the internal specimen changes during drying, a paste specimen that would give a large volume change was prepared. In addition, to study the effect of aggregates (crushed stone, in this case) on the internal deformation, paste specimens were prepared with a particle of crushed stone or crushed brick placed in the centre. Only a single particle was included to be able to visualize the effects around the aggregate without the influence of adjacent particles.

Table 1 shows the mixture proportions of the paste used in this study. In addition to ordinary Portland cement, zirconia balls with a particle size of $0.3 \mathrm{~mm}\left(\right.$ density $\left.6.07 \mathrm{~g} / \mathrm{cm}^{3}\right)$ were mixed into the paste (the samples had $0.75 \%$ of the paste volume as zirconia balls) to provide more enhanced intensity patterns in the tomography images for improving the accuracy of the image measurements.

Table 1. Mixture proportions of paste.

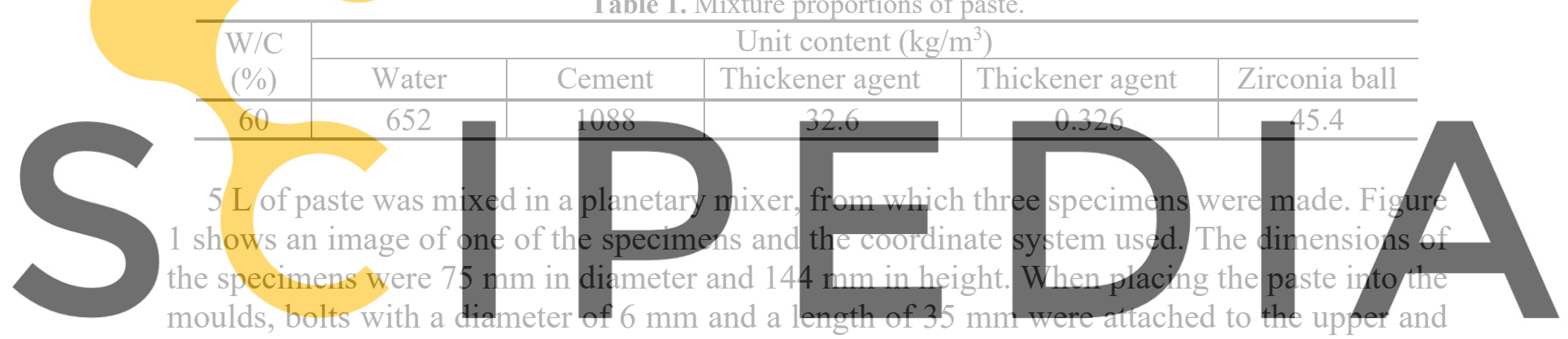

lower surfaces of the specimen. For two specimen, crushed stones (surface dry density $2.63 \mathrm{~g}$

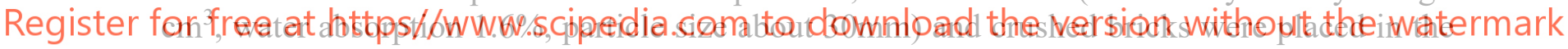
centre in a saturated surface - dry condition.

The samples were demoulded the next day and, immediately after, an epoxy resin was applied to the upper and lower surfaces of the specimen so that moisture could escape only from the sides. In addition, a PVC pipe embedded with 12 ceramic balls (diameter $5 \mathrm{~mm}$ ) was attached to each specimen to reduce mechanical errors and enabling an affine transformation to align images, following Ura, T., Fumoto, T and Takehara, K. (2016). The PVC pipe had 32 holes, with a diameter of $1 \mathrm{~cm}$, arranged from the vertical-centre to the bottom to not prevent moisture dissipation. The specimens were stored in a constant temperature and humidity chamber at a $20 \pm 1{ }^{\circ} \mathrm{C}$ and a humidity of $60 \pm 5 \%$.

\subsection{Measurement Method}

Length change measurements and X-ray CT scans were performed after drying periods of 0,5 , $8,13,21,35$ and 134 days. Shrinkage strain was measured according to the measurement method of JIS A 1129-3. The X-ray CT imaging was performed using an apparatus that were shows in Fumoto, T. (2013) in detail. For each CT measurements, the center height of the specimen $\pm 35 \mathrm{~mm}$ was scanned using the imaging parameters shown in Table 2 and with a 
cubic image voxels with a side length of $0.123 \mathrm{~mm}$. 3D deformation measurements inside the specimens were made using digital volume correlation (DVC) with the software TomoWarp2 of Tudisco et al.(2017). For the DVC measurements, the correlation window for the correlation calculation was a cube of about $3 \mathrm{~mm}$ side length and the distance between correlation windows (the node spacing) was about $1.5 \mathrm{~mm}$.

Table 2. X ray scan condition.

\begin{tabular}{ccrrrrr}
\hline $\begin{array}{c}\text { Tube voltage } \\
(\mathrm{kV})\end{array}$ & $\begin{array}{c}\text { Tube current } \\
(\mu \mathrm{A})\end{array}$ & $\begin{array}{c}\text { frame rate } \\
(\text { frame/sec })\end{array}$ & projection & $\begin{array}{c}\text { Resolution } \\
(\mathrm{mm})\end{array}$ & $\begin{array}{c}\text { cupper plate } \\
(\mathrm{mm})\end{array}$ \\
\hline 170 & 100 & & 4 & 2000 & 0.123 & 3 \\
\hline
\end{tabular}

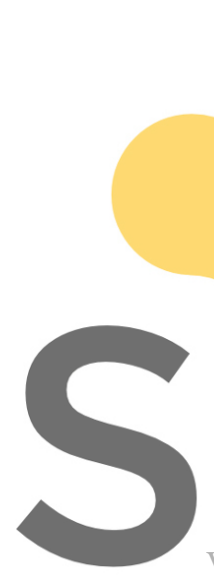

Y direction
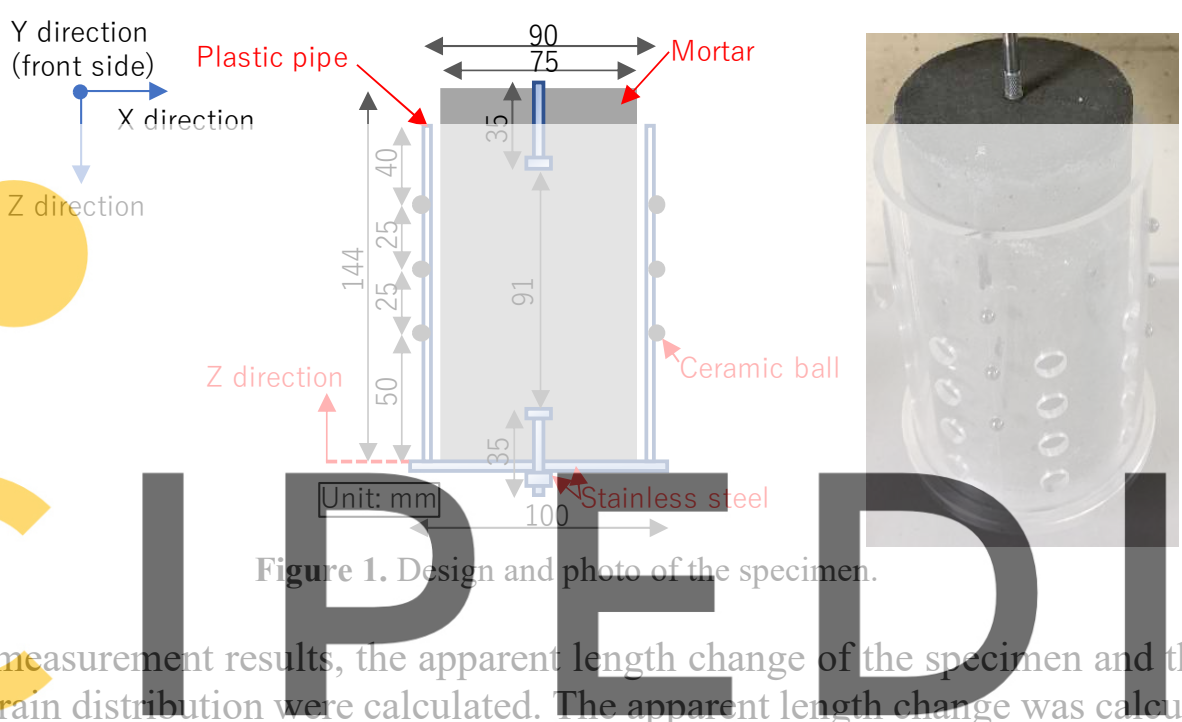

the average value of the DVC-derived z-displacement in two cross-sections positioned at \pm 20

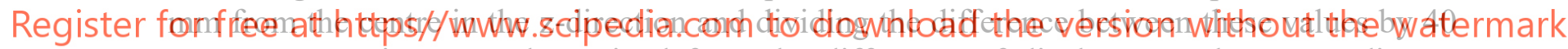
$\mathrm{mm}$. DVC strains were determined from the difference of displacement between adjacent subsets and the local volume strain was calculated by,

$$
\varepsilon_{\mathrm{vol}}=\varepsilon_{\mathrm{x}}+\varepsilon_{\mathrm{y}}+\varepsilon_{\mathrm{z}}
$$

where $\varepsilon_{\mathrm{x}}, \varepsilon_{\mathrm{y}}$ and $\varepsilon_{\mathrm{z}}$ are the normal strains in each direction.

In the X-ray CT images, the intensity indicating the relative value of X-ray absorption is affected by the density and composition. Since the apparent density decreases due to drying from the side of the specimen, the apparent density reduction may be indicated as a decrease in the intensity of the X-ray CT image. Therefore, the moisture content variations were estimated using the intensity distribution in the radial direction over a series of concentric virtual cylinders, centred on the axis of the sample, of $2.5 \mathrm{~mm}$ thickness and spanning a height of $\pm 25 \mathrm{~mm}$ from the z-direction centre of the specimen in the X-ray CT images. The average value of the intensity distribution was calculated over each cylinder, and the transition of the average intensity from the surface to the inside of the specimen was calculated. 


\section{Experimental Results and Discussion}

\subsection{Shrinkage Strain}

Figure 2 shows the shrinkage strain as a function of time obtained from the length change measurements. In the case of the paste, shrinkage strain began to increase from the start of drying and increased linearly until the drying period of 35 days, reaching about $3200 \times 10^{-6}$. After that, the shrinkage strain increased to about $6000 \times 10^{-6}$ after 134 days of drying and appear to have reach a steady state. The length change for the crushed stone and crushed brick samples was smaller than that of the paste by about $500 \times 10^{-6}$ at 35 days and about $300 \times 10^{-6}$ at 134 days of drying. This is considered to result from the reduced paste volume due to the presence of the stone/brick particles.

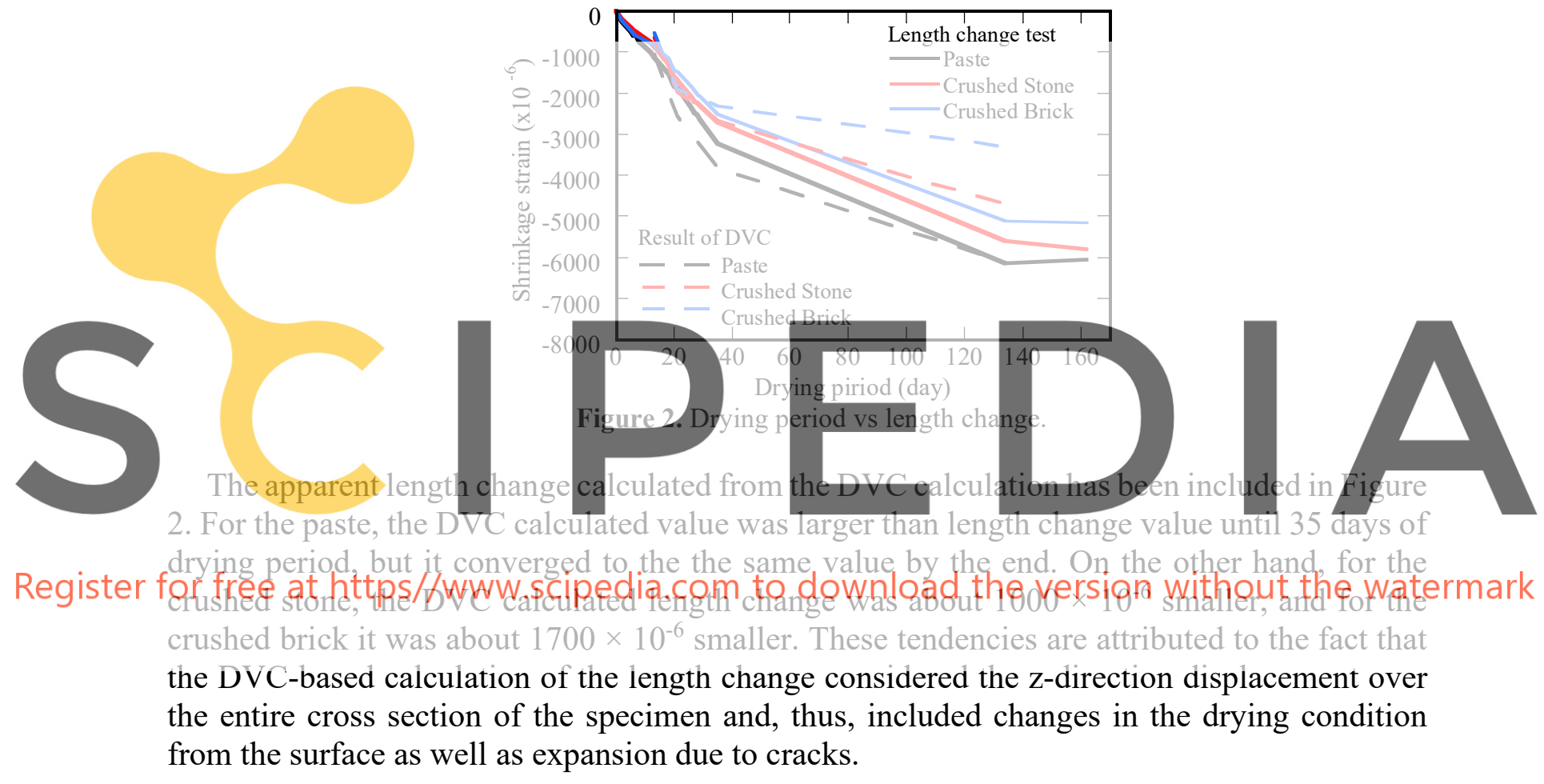

\subsection{Observation of X-Ray CT Images}

Figure 3 shows $\mathrm{XZ}$ cross-section images for each drying time the three samples. For the paste sample, the image intensity is seen to decreased as the drying period increases and the specimen has only a small crack after 35 days of drying. However, for the samples containing a particle, cracks can be seen at early drying stages, which became longer and wider as the drying progresses. Some of the cracks appear to have occurred at positions where there is an abrupt change in the particle surface angle. These cracks are thought to have formed due to constraints through adhesion at the particle surface.

Figure 4 shows the intensity change as a function of position from sample surface for the paste specimen. The intensity can be seen to have decreased near the surface at $5-8$ days of drying. After about 8 days, the intensity changed significantly near the centre. After 134 days 
of drying, the intensity reached almost the same value at the centre as at the surface. As shown in Figure 2, it is expected that the water movement had reached an equilibrium by this time.

Figure 5 shows the intensity rate based on intensity difference between saturation and equilibrium, which can be regarded as the rate of water reduction until reaching equilibrium under this condition. After drying for 5 days, $5-50 \%$ of the water up to $20 \mathrm{~mm}$ depth evaporated through the surface. After 13 days of drying, the water content in the first $5 \mathrm{~mm}$ in depth reduced very slowly. On the other hand, the water from more than $5 \mathrm{~mm}$ in depth moved rapidly.

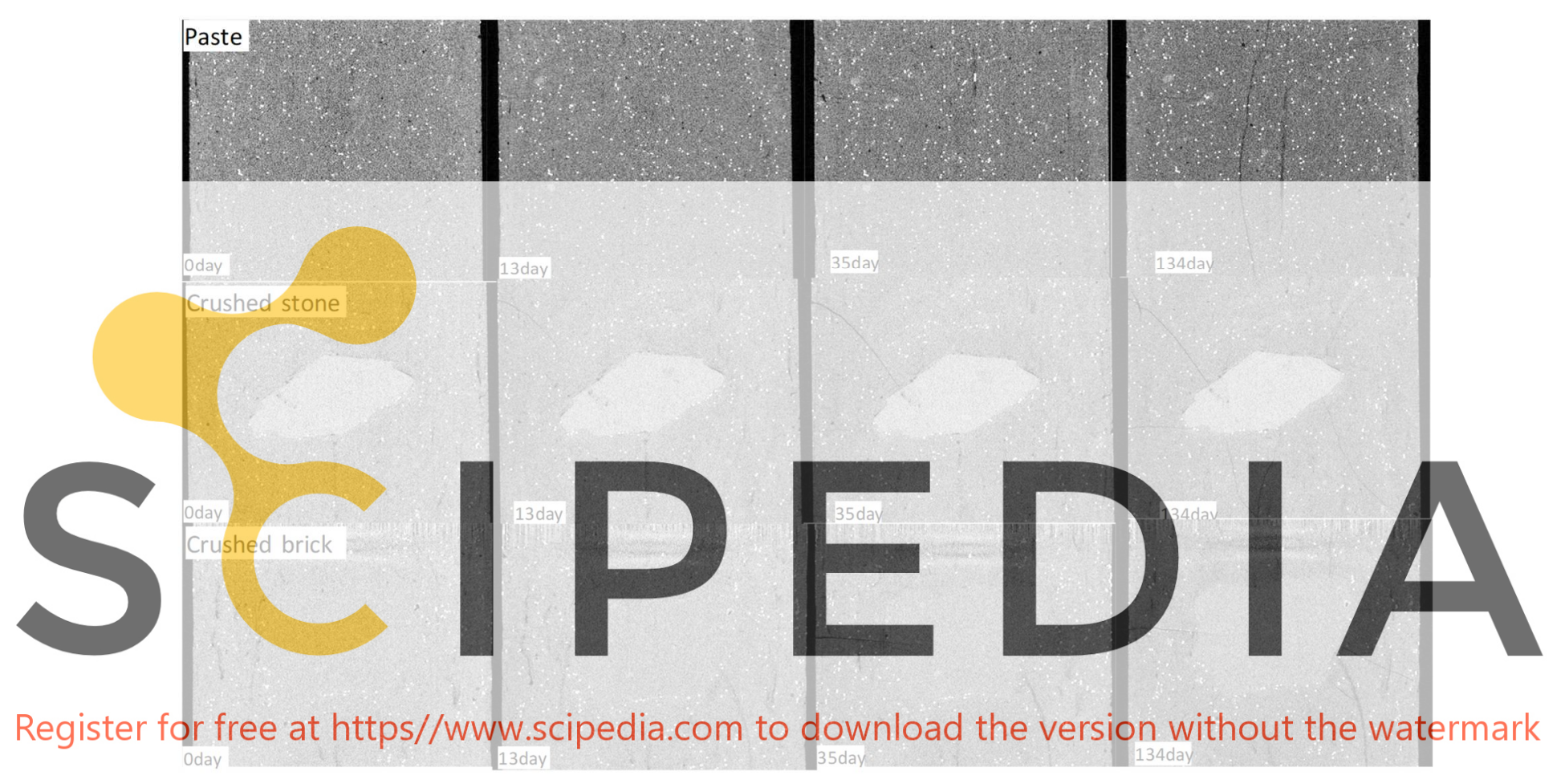

Figure 3. XZ cross-sectional images for each dry material age for paste, crushed stone, and crushed brick.

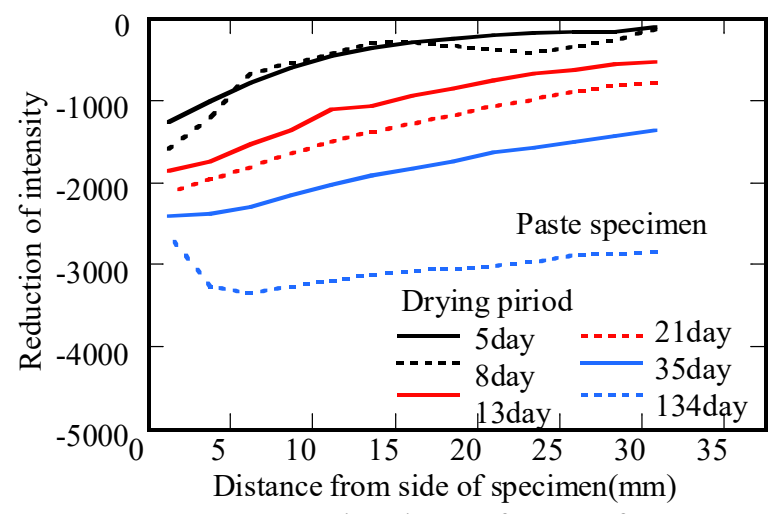

Figure 4. Intensity change from surface. 


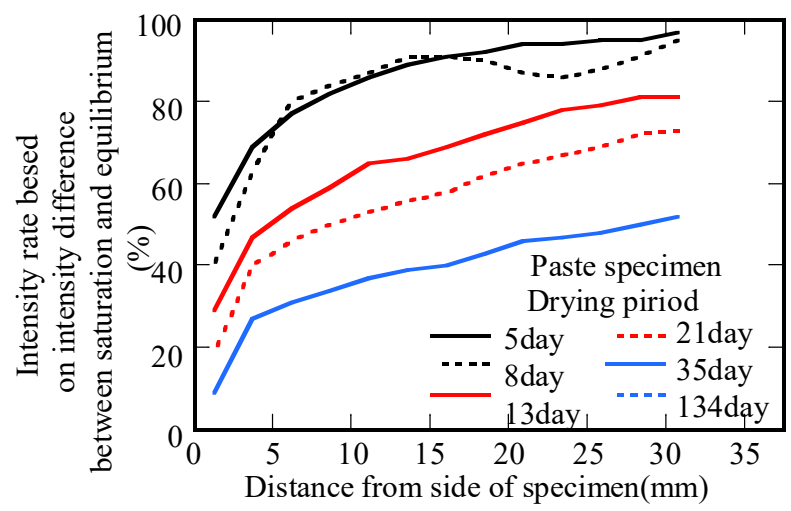

Figure 5. Intensity rate based on intensity difference between saturation and equilibrium.

\subsection{Measurement Results Using DVC}

Figure 6 shows the volumetric strain distribution inside the 3 specimens based on DVC measurement.

In the case of the paste specimen, there was no particular change over the first 8 days drying period. However, the shrinkage strain region can be seen to extend from the side surface after 13 days and extends to about $20 \mathrm{~mm}$ depth from the side at 21 days. From 35 to 134 days of drying, the shrinkage strain region widened on the whole. Localised regions of high dilation indicate the formation of cracks.

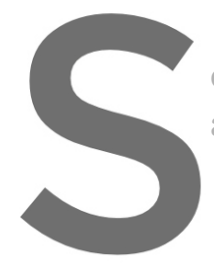

In the case of the specimens can be seen that the shrinkage strain incre after 35 days of drying, the shrinkage strain around the particles
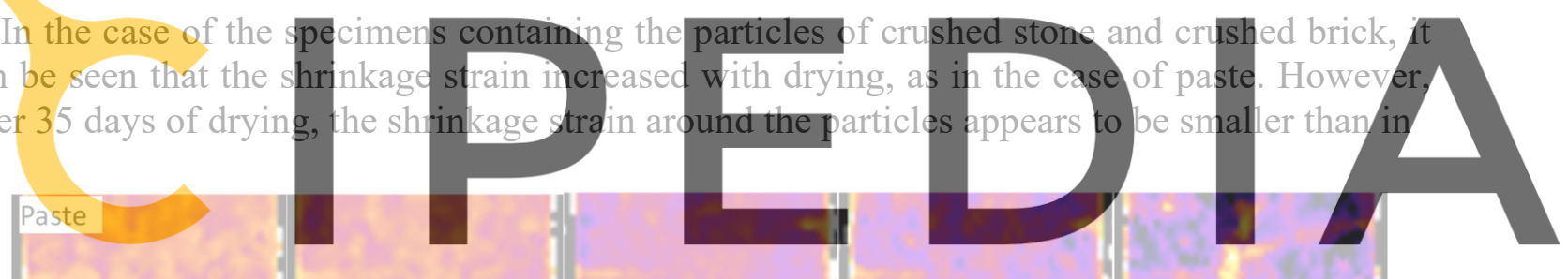

Register for free at https//www.scipedia.com to download the version without the watermark

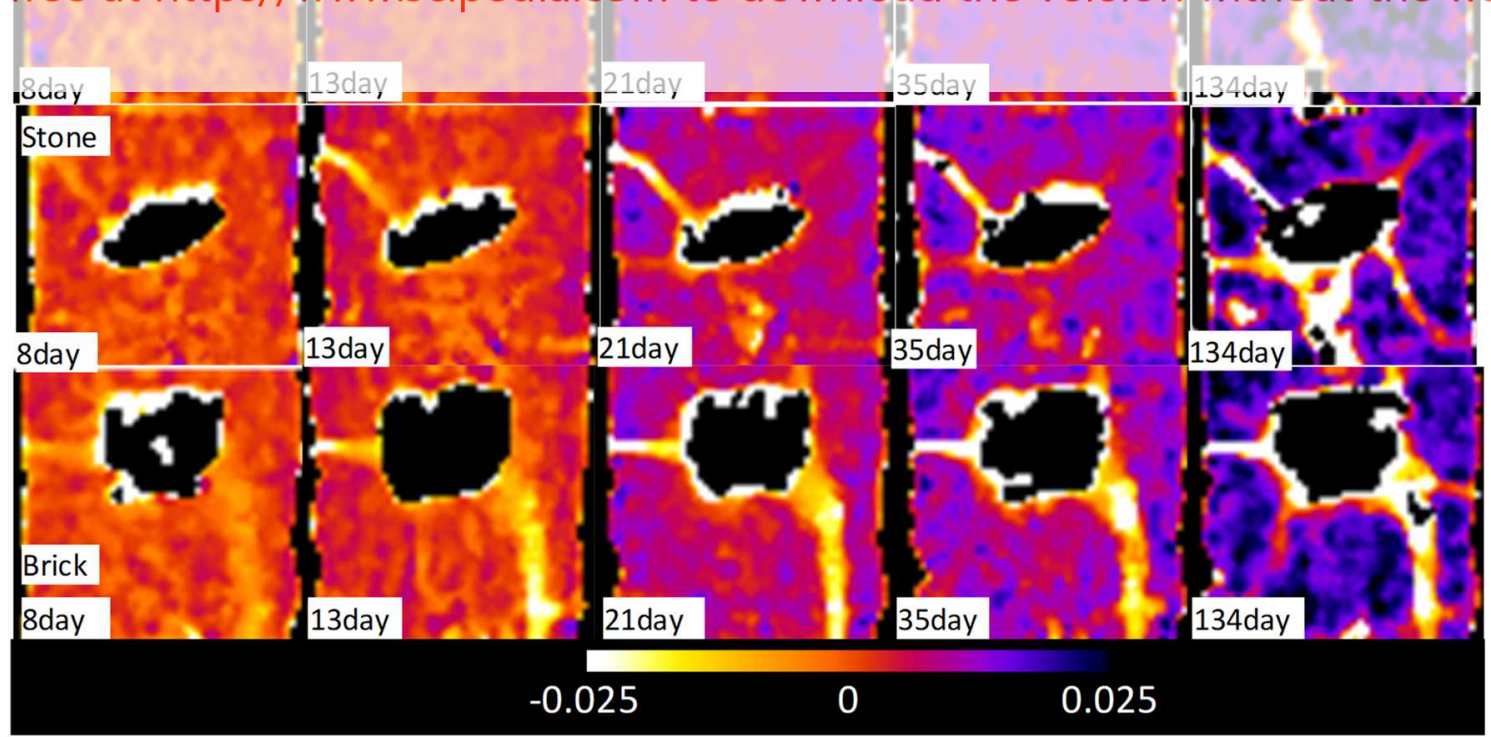

Figure 6. Volumetric strain distribution inside the specimen based on DVC measurement. 
other regions. Several areas of minor dilation can be observed after 8 days of drying which evolve to cracks in the later stages, these appear to form from the particle surfaces early in the drying sequence and then their width increases with further drying. It is likely that the cracks initiated at the particle surfaces due to adhesion between the particles and the paste constraining the shrinkage process.

The results presented above show that the shrinkage strain distribution in the cement paste due to drying from the surface could be measured. In addition, the relaxation of the shrinkage strain was observed around particles, but it was obscured, in part, due to the occurrence of cracks. In future work, specimens that do not crack easily, such as mortar specimens, could avoid this issue.

In addition, the results for the paste specimen in Figures 2 and 3 show that a noticeable shrinkage strain occurred when there was over $50 \%$ difference in the moisture content between saturation and equilibrium. This is considered to indicate that relationships between the internal moisture and volumetric strain can be investigated using $\mathrm{X}$ ray $\mathrm{CT}$.

\section{Summary}

The purpose of this study was to perform length change tests on cylindrical specimens of cement paste using X ray CT as a basic study for measuring drying shrinkage distribution inside concrete and to make measurements using X-ray CT images at different stages of drying. The key conclusions from this work are:
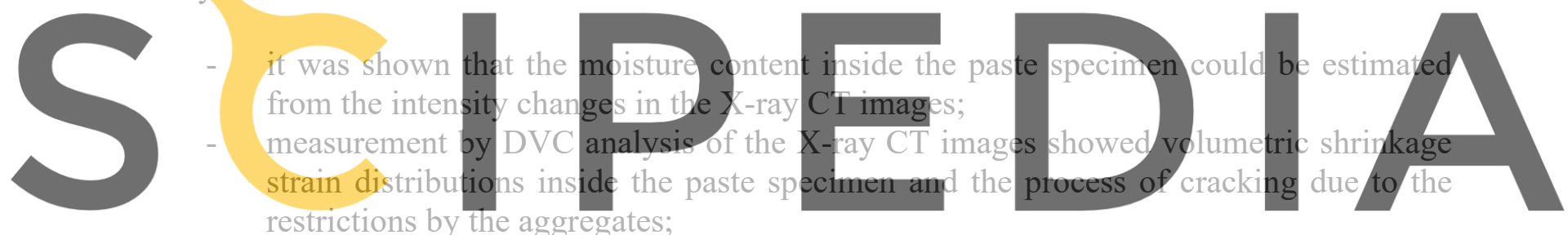

By integrating the results on image intensity changes and the volumetric strain, it will be

Register for free at

change inside a specimen.

- In this study and the given conditions, a noticeable shrinkage strain occurred when the of the difference of moisture content between saturation and equilibrium was above $50 \%$.

In summary, this study has demonstrated that internal moisture movement and volume changes due to drying can be considered by image measurements on X-ray CT images, which opens the door to further investigations in the future.

\section{Acknowledgment}

This work was supported by JSPS KAKENHI Grant Number JP17K06522.

\section{ORCID}

Takayuki Fumoto: https://orcid.org/0000-0001-8478-4145

Masaru Abuku: https://orcid.org/0000-0001-7090-4732

Stephen A. Hall: https://orcid.org/0000-0002-5232-4942 


\section{Reference}

Alexander, MG. (1996). Aggregates and the Deformation Properties of Concrete, ACI Materials Journal, Vol. 93, No. 6, pp. 569-577.

Fumoto, T. (2013). Development of a new Industrial X-Ray CT System and its Application to Compression Test of Polymer Concrete (in Japanese), Journal of Japan Society of Civil Engineers E2 (Materials and Concrete Structures), Vol. 69, No. 2, pp. 182-191. doi: 10.2208/jscejmcs.69.182

Fumoto, T. and Hall, S (2019). Deformation of Mortar around an Aggregate in a Trial Specimen Under Compressive Stress Using X ray CT and DVC, International Conference on Tomography of Materials \& Structures.

Fumoto, T., Mizuno, S. and Ozawa, M. (2016). Evaluation of Fire Damage Distribution of Concrete by X-Ray Computed Tomography, Fourth International Conference on Sustainable Construction Materials and Technologies, http://www.claisse.info/Proceedings.htm

Hong, S., Liu, P., Zhang, J., Xing, F. and Dong, B. (2019) Visual \& quantitative identification of cracking in mortar subjected to loads using X-ray computed tomography method, Cement and Concrete Composites, Vol. 100, pp. 15-24. doi: 10.1016/j.cemconcomp.2019.03.010

IIS A 1129-3 (2010). Measuring method for length change of mortar and concrete-Part 3: Dial gauge method.

Sant, G. and Weiss, J. (2009). Using X-Ray Absorption to Assess Moisture Movement in Cement-Based Materials, Journal of ASTM International, Vol. 6, No. 9, pp. 1-15, doi: 10.1520/JAI102234

Tudisco E., Andò, E., Cailletaud, R. and Hall, S. (2017). TomoWarp2: A local digital volume correlation code, SoftwareX, Vol.6, pp. 267-270, 2017

Ura, T., Fumoto, T and Takehara, K. (2016). Basic research on accuracy of internal displacement measurement using the newly developed X-ray CT system (in Japanese), Proceedings of the Japan Concrete Institute, Vol.38, No.1, pp.429-434.

Zhanga, W., Zakariaab, M. and Hama, Y (2013). Influence of aggregate materials characteristics on the drying

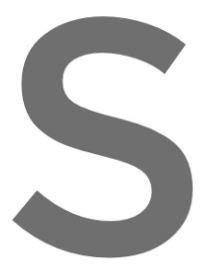
shrinkage properties o
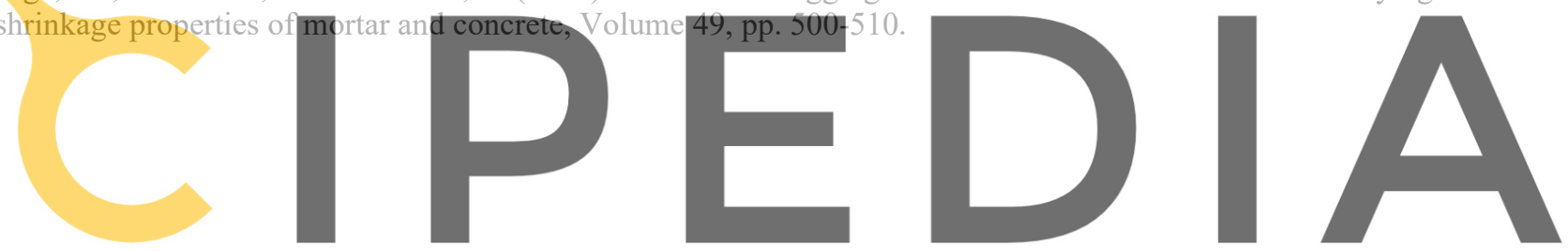

Register for free at https//www.scipedia.com to download the version without the watermark 